\title{
Effect of egg mass of the white Italian goose on fertilisation, loss of weight during the incubation period, hatchability and gosling quality
}

\author{
Sreten Mitrovic ${ }^{1}$; Cvijan Mekic ${ }^{1}$, Milena Milojevic*1, Maja Radoicic Dimitrijevic ${ }^{1}$, \\ Vera Đekic $^{2}$ and Vladan Đermanovic ${ }^{1}$
}

University of Belgrade,

Faculty of Agriculture, Serbia.

Received: 12-06-2017

Accepted: 07-03-2018

DOI: $10.18805 /$ ijar.B-787

\section{ABSTRACT}

The main purpose of the study was to determine the effect of egg mass and egg weight groups (group I eggs under $160 \mathrm{~g}$, group II egg mass $160 \mathrm{~g}$ to $180 \mathrm{~g}$ and group III eggs over $180 \mathrm{~g}$ ) on incubation results, loss of egg weight (moist) during incubation, gosling hatchability and the relative share of the gosling in the egg mass. Eggs with mass between $160 \mathrm{~g}$ and $180 \mathrm{~g}$ (group II) demonstrated the highest fertilisation rate (91.28\%) and the highest hatchability out of the number of incubated eggs $(83.14 \%$ ), while the eggs from the group I (lighter than $160 \mathrm{~g}$ ) showed the highest number of gosling hatchability out of the number of fertilised eggs $(91.08 \%)$. The lowest embryo mortality was that of the group I (5.17\% and $6.06 \%$ ), while the highest is reported for the group III (14.29\% and $16.67 \%)$. The lowest relative loss of egg mass (moist) by day 25 of the incubation period was established for the group I eggs (10.98\%), and the highest for the group III $(11.71 \%)$, with a statistically significant $(\mathrm{P}<0.01)$ difference of $-0.73 \%$. Other differences were not statistically significant $(\mathrm{P}>0.05)$. Gosling percentage in the egg mass was significantly higher $(\mathrm{P}<0.001)$ in the group III of incubated eggs $(67.81$ $\%)$ than in the group II (66.61 \%) and the group I (65.24\%).

Key words: Egg weight, Geese, Gosling weight Incubation, Weight loss.

Abbreviations: EWG: egg weight group INTRODUCTION

The main difference between the reproduction of birds and mammals is the fact that birds do not give birth to live offspring as mammals do. Instead, the new organism develops outside the womb, in the egg which must be fertilised. Well fertilised egg is an embryo "package" with all the necessary nutrients which facilitate its development until it is hatched and for a few days after hatching. Results of the poultry offspring production, i.e. poultry embryo development depend during its embryo development - apart from its genetical basis - on several non-genetic factors. These are: goose age, egg mass, egg storage period, incubation technology, egg shape index, egg laying season, etc. Certain number of authors have conducted research on the above matter, primarily related to establishing incubation values of chicken eggs, while few of them researched on other poultry, particularly geese.

The following authors have significantly contributed to establishing genetic and non-genetic factors influencing incubation values of goose eggs and gosling quality: Meir and Ar (1991), Bednarczyk and Rosiñski (1999), Mazanowski and Chelmonska (2000), Rosiñski (2000), Mazanowski and Adamski (2002), Bobko and Svetlik (2002), Pakulska. (2003) Saatci et al. (2005), as well as: Mazanowski and Bernacki (2006), Meir and $\operatorname{Ar}(2008)$, Đermanovic et al. (2008), Rachwal (2008), Rabsztyn et al. (2010), Scripnic and Modvala (2010), RazmaitP et al. (2014), Kucharska-Gaca et al. (2016a), Kucharska-Gaca et al. (2016b), Mitrovic et al. (2016).

Studies similar to ours researching incubational values of different goose races and strains (Italian White WD1 and WD3, Kuban and White Koluda goose) with particular focus on the genotype, age, reproductive cycle season and effect of the egg mass on fertilisation, embryo mortality, egg weight loss during the incubation period, hatchability and quality (mass) of hatched goslings, were carried out by Bednarczyk and Rosiñski (1999), Bobko and Svetlik (2002), Meir and Ar (2008), Kucharska-Gaca et al. (2016b) and Mitrovic et al. (2016). These authors conclude that most of the reproductive indicators are affected by genotype, phase of the reproductive cycle (egg laying season), shape index, egg mass, and that the largest loss of moist in eggs during the incubation period was in the heaviest eggs, and lowest in the lightest eggs.

With an aim to determine effects of egg mass, i.e. egg weight groups of Italian White Goose on incubation results (egg fertility, embryo mortality, gosling hatchability),

\footnotetext{
*Corresponding author's e-mail: milojevic.milena23@gmail.com

${ }^{1}$ University of Belgrade, Faculty of Agriculture, Serbia.

${ }^{2}$ Center for Small Grains of Kragujevac, Kragujevac, Serbia.
} 
loss of humidity during incubation, egg mass and relative percentage of gosling in egg mass, a research was conducted on the family farm „Anser” (Triješnica, BiH), engaged in commercial goose breeding as well as laying eggs and oneday gosling production.

\section{MATERIALS AND METHODS}

The experimental part of the research was carried out on the family farm "Anser" (Triješnica, BiH), engaged in parent flock breeding of the of Italian White Goose in the semi-extensive system, as well as laying eggs and one-day gosling production.

Four hundred (400) eggs randomly collected were used as start-up experimental material. Eggs were successively incubated during the laying season from February until June. During the incubation period, the number and percentage of fertilised eggs was established, the number of goslings hatched out of the number of incubated and out of the number of fertilised eggs, as well as the number and percentage of eggs with dead embryos. Before that, eggs were separated into three groups: group I with eggs under $160 \mathrm{~g}$ (<160 g), group II with egg mass between $161 \mathrm{~g}$ and $180 \mathrm{~g}$, and group III which consisted of eggs over $180 \mathrm{~g}(>180 \mathrm{~g})$.

Group II had the largest number of eggs and group III the least. This means that all eggs were weighed individually, egg shells were marked with pencil and were disinfected with formaldehyde vapours before being laid into the incubator. The egg mass was individually measured before laying into the incubator and on the 25th day of incubation, as well as the mass of dry goslings after the hatching. Based on the egg mass on the first and on the 25 th day of incubation, the absolute and relative egg mass loss in the mentioned period was determined for each weight group.

When eggs were moved from the incubator to the hatchery area within the incubator (day 25), they were individually placed into the specially constructed compartments to be certain which gosling is hatched from which egg. At the end of the incubation period, one-day gosling mass was established which enabled the calculation of the relative percentage of the gosling in the egg mass, i.e., the gosling percentage (GP) in the egg mass, according to the following formula: GP $=[$ (gosling mass/egg mass $) \mathrm{x}$ 100]. Particular attention was given to those eggs from which healthy and vital goslings were hatched.

Basic data analysis was carried out with Stat. Soft. Inc. (2003) STATISTICA (data analysis software system), version 6 , by applying the common variation-statistical methods (descriptive statistics). For the majority of the indicators monitored in each of the egg groups, following was calculated: arithmetic mean (x), arithmetic mean error (Sx), standard deviation (SD) and variance coefficient (VC). The testing of the significance of difference between the researched incubation characteristics was carried out with corresponding variance analysis models (completely random experimental model -3 egg weight groups); $\mathrm{Yij}=\mu+(\mathrm{EWG}) \mathrm{i}$ + eij with equal and unequal number of repetitions per tretment, where:

Yij - value of the monitored characteristic (egg mass, loss of egg mass by day 25 in grams and percentages, one-day gosling mass in grams and the gosling percentage in the egg mass). (EWG)i - effect of the weight group; $i=1,2 \ldots \mathrm{k} ; \mathrm{j}=1,2, \ldots \mathrm{n}$ eij-random error.

\section{RESULTS AND DISCUSSION}

Based on the first indvidual measuring, weight group I consisted of 116 eggs (29\%), weight group II consisted of 172 eggs ( $43 \%$ ), and weight group III consisted of 112 eggs ( $28 \%)$ - a total of 400 eggs (100\%). This means that group II contained the largest number of eggs (161 $180 \mathrm{~g}$ ), while the heaviest group (group III with eggs over $180 \mathrm{~g}$ ) contained the lowest number of eggs.

In general, independently of the egg weight group, the Italian White Goose laying eggs showed substantial incubation values, particularly in relation to gosling hatchability, both out of the number of incubated and the number of fertilised eggs (Table 1).

The data in Table 1 demonstrated that eggs from the group II showed the highest fertilisation rate $(91.28 \%)$, while the group I and III had similar percentage of egg fertilisation $(85.34 \%$ i $85.71 \%$ ). Light eggs (group I) had the lowest embryo mortality $-5.17 \%$ (out of the number of incubated eggs) and $6.06 \%$ (out of the number of fertilised eggs), while the heaviest eggs had the highest number of dead embryos (14.29\% i 16.67\%) during the incubation period.

Gosling hatchability out of the number of incubated eggs was largest in the weight group II $(83.14 \%)$, then in the group I $(80.17 \%)$, and smallest in the group III $(71.43 \%)$, while the gosling hatchability out of the number of fertilised eggs was highest in the egg weight group I (93.94\%), followed by the group II (91.08\%), and lowest, again, in the weight group III $(83.33 \%)$.

Out of the total of 400 eggs, 352 were fertilised ( 88 $\%), 48$ were unfertilised (12\%), 16 had dead embryos $(9.00 \%$ i $10.23 \%$ ), while the gosling hatchability was at a relatively high level: 316 healthy and vital goslings were hatched, which amounts to $79 \%$ of the number of incubated eggs and $89.77 \%$ out of the number of fertilised eggs (Table 1).

In the following part of the article, particular attention was given to those eggs from which goslings were hatched, because this category was of crucial importance for successful production of one-day goslings. In terms of the egg weight group, out of the total of 316 eggs from which goslings were hatched (Table 2), 93 eggs, i.e. goslings 
Table 1: Fertilisation and hatchability of goose eggs as per weight groups.

\begin{tabular}{|c|c|c|c|}
\hline Egg Weight Group & Egg Category & No. of Eggs & Percentage \\
\hline \multirow[t]{7}{*}{ I - Light eggs $(<160$ g) } & Total no. of eggs incubated & 116 & 100.00 \\
\hline & Fertilised eggs & 99 & 85.34 \\
\hline & Unfertilised eggs & 17 & 14.66 \\
\hline & Eggs with dead embryos (A) & 6 & 5.17 \\
\hline & Eggs with dead embryos (B) & 6 & 6.06 \\
\hline & Goslings hatched (A) & 93 & 80.17 \\
\hline & Goslings hatched (B) & 93 & 93.94 \\
\hline \multirow{7}{*}{$\begin{array}{l}\text { I - Medium weight } \\
\text { eggs(160-180 g) }\end{array}$} & Total no. of eggs incubated & 172 & 100.00 \\
\hline & Fertilised eggs & 157 & 91.28 \\
\hline & Unfertilised eggs & 15 & 8.72 \\
\hline & Eggs with dead embryos (A) & 14 & 8.14 \\
\hline & Eggs with dead embryos (B) & 14 & 8.92 \\
\hline & Goslings hatched (A) & 143 & 83.14 \\
\hline & Goslings hatched (B) & 143 & 91.08 \\
\hline \multirow{7}{*}{$\begin{array}{l}\text { III - Heavy eggs } \\
(>180 \mathrm{~g})\end{array}$} & Total no. of eggs incubated & 112 & 100.00 \\
\hline & Fertilised eggs & 96 & 85.71 \\
\hline & Unfertilised eggs & 16 & 14.29 \\
\hline & Eggs with dead embryos (A) & 16 & 14.29 \\
\hline & Eggs with dead embroys (B) & 16 & 16.67 \\
\hline & Goslings hatched (A) & 80 & 71.43 \\
\hline & Goslings hatched (B) & 80 & 83.33 \\
\hline \multirow[t]{7}{*}{$\mathrm{I}+\mathrm{II}+\mathrm{III}$} & Total no. of eggs incubated & 400 & 100.00 \\
\hline & Fertilised eggs & 352 & 88.00 \\
\hline & Unfertilised eggs & 48 & 12.00 \\
\hline & Eggs with dead embryos (A) & 36 & 9.00 \\
\hline & Eggs with dead embryos (B) & 36 & 10.23 \\
\hline & Goslings hatched (A) & 316 & 79.00 \\
\hline & Goslings hatched (B) & 316 & 89.77 \\
\hline
\end{tabular}

A) - Out of total incubated eggs; (B) - Out of total fertilised eggs.

belonged to group I (29.43\%), 143 goslings came from group II $(4.25 \%)$ and 80 from group III $(25.32 \%)$.

The average egg mass was $149.21 \mathrm{~g}$ (group I), $169.76 \mathrm{~g}$ (group II) and $190.26 \mathrm{~g}$ (group III). Established differences in the average mass between the egg weight groups were statisticlly significant $(\mathrm{P}<0.01)$, and the same applies to the average mass of the hatched goslings (Table 3 ). The greatest loss of the egg mass by day 25 of incubation is reported for the heaviest group (group III $-11.71 \%$ ), and the least in the light eggs group (I grupa - 10.98\%), and the difference of $-0.73 \%$ was statistically significant $(\mathrm{P}<0.01)$, while other differences between the groups in terms of the relative egg mass loss by day 25 of incubation, were not statistically significant $(\mathrm{P}>0.05)$. The largest relative gosling percentage in the egg mass was that of the group III - 67,81\%, followed by the group II - 66,61\% and the smallest is reported for the group I - 65,24\% (Table 2). This means that a statistically significant $(\mathrm{P}<0,001)$ growth of gosling mass and the gosling percentage in the egg mass in concurrence with the growth of the egg mass is reported (Table 3 ).

It was evident from the Table 3 that the egg mass (egg weight group) had an effect on the relative and absolute loss of the egg mass during the incubation period, particularly on the gosling weight and the gosling percentage in the egg mass.

Furthermore, the average egg mass for all three egg weight groups was $168.91 \mathrm{~g}$; egg mass loss by day 25 of incubation was $19.16 \mathrm{~g}$ or $11.35 \%$; average one-day gosling mass was $112.50 \mathrm{~g}$, and the relative percentage of the gosling in the egg mass was $66.51 \%$ (Table 2).

In our research, the best fertilisation rate was demonstrated by the medium weight eggs (group II $91.28 \%$ ), while heavy and light eggs showed considerably lower fertilisation (group III - 85.71\%; group I - 85.34\%), thus $88.00 \%$ in all eggs. This means that the best egg fertilisation rate was demonstrated by the Italian White Goose eggs of 160 - 180 g egg mass. Kucharska - Gace et al. (2016b) reported the highest fertilisation rate of the White Koluda geese in the lightest egg group (141 to $160 \mathrm{~g} \mathrm{-}$ $75.5 \%$ ), and the lowest in the heaviest egg group (200 to $220 \mathrm{~g}-65.6 \%$ ), and their hatchability percentages of all weight groups are considerably lower than the same in our research. Somewhat higher hatchability percentage $(81.5 \%)$ was reported by the same authors (2016a), also of the White Koluda geese, but the fertilisation was insignificantly lower than that reported in our study for all weight groups (88.00 
Table 2: Mean values and variability of the main traits of eggs from which goslings were hatched

\begin{tabular}{|c|c|c|c|c|c|}
\hline Egg traits & $\begin{array}{l}\text { Statistical } \\
\text { indicator }\end{array}$ & Group I & Group II & Group III & Total \\
\hline \multirow{5}{*}{ Egg mass day 1 (g) } & \multirow{3}{*}{$\begin{array}{l}\bar{x} \\
\mathrm{n}\end{array}$} & 149.21 & 169.76 & 190.26 & 168.91 \\
\hline & & 93 & 143 & 80 & 316 \\
\hline & & 0.93 & 0.53 & 0.88 & 0.95 \\
\hline & $\mathrm{S} x$ & 8.96 & 6.30 & 7.91 & 16.91 \\
\hline & $\begin{array}{l}\text { S } \\
\text { C.V. }\end{array}$ & 6.00 & 3.71 & 4.16 & 10.01 \\
\hline \multirow{5}{*}{ Egg mass loss by day 25 (g) } & $\bar{x}$ & 16.40 & 19.27 & 22.20 & 19.16 \\
\hline & $x^{x}$ & 93 & 143 & 80 & 316 \\
\hline & & 0.30 & 0.22 & 0.28 & 0.19 \\
\hline & $\mathrm{S} x$ & 2.92 & 2.66 & 2.25 & 3.45 \\
\hline & $\begin{array}{l}\text { S } \\
\text { C.V. }\end{array}$ & 17.80 & 13.80 & 11.31 & 18.01 \\
\hline \multirow{5}{*}{ Egg mass loss by day $25(\%)$} & $\bar{x}$ & 10.98 & 11.38 & 11.71 & 11.35 \\
\hline & $n^{\lambda}$ & 93 & 143 & 80 & 316 \\
\hline & n- & 0.17 & 0.15 & 0.14 & 0.09 \\
\hline & $\mathrm{S} x$ & 1.67 & 1.86 & 1.22 & 1.68 \\
\hline & $\begin{array}{l}\text { S } \\
\text { C.V. }\end{array}$ & 15.21 & 13.71 & 10.42 & 14.80 \\
\hline \multirow{5}{*}{ One-day gosling mass (g) } & $\bar{x}$ & 97.37 & 113.0 & 129.06 & 112.50 \\
\hline & $n$ & 93 & 143 & 80 & 316 \\
\hline & - & 0.68 & 0.48 & 0.79 & 0.73 \\
\hline & $\mathrm{S}_{x}$ & 6.55 & 5.76 & 7.11 & 12.94 \\
\hline & $\mathrm{S}$ & 6.73 & 5.10 & 5.51 & 11.50 \\
\hline \multirow{5}{*}{ Gosling $\%$ in the egg mass } & $\frac{\text { C.V. }}{x}$ & 65.24 & 66.61 & 67.81 & 66.51 \\
\hline & $n^{x}$ & 93 & 143 & 80 & 316 \\
\hline & ${ }^{11}$ & 0.23 & 0.18 & 0.21 & 0.11 \\
\hline & $\mathrm{S} x$ & 2.24 & 2.19 & 1.85 & 1.96 \\
\hline & $\begin{array}{l}\mathrm{S} \\
\mathrm{C}_{\mathrm{V}}\end{array}$ & 3.43 & 3.29 & 2.73 & 2.95 \\
\hline
\end{tabular}

$\%)$. Similar and somewhat poorer results in pure breeds and mongrels obtained by the reciprocal interbreeding of various goose races (including the Italian White) was reported by Mitrovic et al. (2016), Mazanowski and Chelmonska (2000), Mazanowski and Adamski (2002), Mazanowski and Bernacki (2006). Rosiñski (2000) and Đermanovic et al. (2008) report poorer and considerably lower egg fertilisation rate and gosling hatchability of Italian White Goose and tworace mongrels. Kucharska-Gaca et al. (2016b) reported the highest number of hatched out of the number of incubated eggs and the number of fertilised eggs in the lightest egg weight group $(57.8 \%$ and $79.3 \%)$, and the lowest in the heaviest egg group (48.2\% and $73.7 \%)$, which is considerably lower than in comparison with our results. Furthermore, Bednarczyk and Rosiñski (1999) report considerably lower and lower gosling hatchability out of the number of fertilised eggs of two Italian White goose types (strains) (WD1 and WD2) and Kuban goose (67.3\%, 78.5\% and $78.5 \%$ ). The lowest percentage of the gosling hatchability $(61.1 \%)$ out of the number of incubated eggs was reported by Pakulska et al. (2003).

One of the factors causing a relatively low gosling hatchability out of the number of fertilised eggs was high embryo mortality, which ranged between $14.9 \%$ and $22.5 \%$
(Bednarczyk and Rosiñski, 1999), while Kucharska-Gaca et al. (2016b) report the lowest embryo mortality out of the number of incubated and the number of fertilised eggs to be in the group III (11.3\% and $16.5 \%)$ and the highest in the group II (13.8\% and 20.9\%). Scripnic and Modvala (2010) point out that moistening the eggs of the Italian White goose during the incubation period with the potassium permanganate $-\mathrm{KMnO}_{4}(10 \mathrm{~g} / 101$ water $)$ has a positive effect on the hatchability percentage and gosling quality. Furthermore, Rachwal (2008) concludes that the egg mass affects embryo mortality in the sense that lighter eggs have lower embryo mortality, and vice versa.

Saatci et al. (2005) have reported in all goose strains (white, yellow, multicolour and black), and Đermanovic et al. (2008) in two race mongrels, a considerably smaller egg mass (under $151 \mathrm{~g}$ ) of the Italian White goose than that obtained in our research (the average mass of all incubated eggs was $168.91 \mathrm{~g}$ ). Depending on the goose mongrels, Mazanowski and Chelmonska (2000), Mazanowski et al. (2002), Mazanowski and Bernacki (2006) have reported a larger average egg mass ( $184 \mathrm{~g})$ than the one established in our study (168.91 g), but also considerably smaller (148 g). Similarly, Razmaite et al. (2014) report higher (186.69 g 3rd year of breeding) in Lithuanian VishtinPs geese, and 
Table 3 : Significance of difference between the main egg and gosling traits.

\begin{tabular}{|c|c|c|c|}
\hline Egg and gosling traits & Egg group & Difference & Significance \\
\hline \multirow[t]{3}{*}{$\overline{\text { Egg mass on day } 1 \text { (g) }}$} & I - II & -20.55 & $* * *$ \\
\hline & I - III & -41.05 & $* * *$ \\
\hline & II - III & -20.50 & $* * *$ \\
\hline \multirow[t]{3}{*}{ Egg mass loss by day 25 (g) } & $\mathrm{I}-\mathrm{II}$ & -2.87 & $* * *$ \\
\hline & I-III & -5.80 & $* * *$ \\
\hline & II-III & -2.93 & $* * *$ \\
\hline \multirow[t]{3}{*}{ Egg mass loss by day $25(\%)$} & $\mathrm{I}-\mathrm{II}$ & -0.40 & NS \\
\hline & I-III & -0.73 & $* *$ \\
\hline & II- III & -0.33 & NS \\
\hline \multirow[t]{3}{*}{ One-day gosling mass $(\mathrm{g})$} & I - III & -15.65 & $* * *$ \\
\hline & I- II & -31.69 & $* * *$ \\
\hline & II - III & -16.04 & $* * *$ \\
\hline \multirow[t]{3}{*}{ Gosling $\%$ in the egg mass } & $\mathrm{I}-\mathrm{II}$ & -1.37 & $* * *$ \\
\hline & I - III & -2.57 & $* * *$ \\
\hline & II - III & -1.20 & $* * *$ \\
\hline
\end{tabular}

$\mathrm{NS}-\mathrm{P}>0.05 ; * * \mathrm{P}<0.01 ; * * *-\mathrm{P}<0.001$.

smaller (123.40 g - 1st year of breeding) egg mass. Somewhat smaller egg mass of the Italian White goose (under $168 \mathrm{~g}$ ) and considerably lower of a strain of the Kuban goose (under $143 \mathrm{~g}$ ) was reported by Bednarczyk and Rosiñski (1999). Rabsztyn et al. (2010) have reported considerably smaller average egg mass of approximately $165 \mathrm{~g}$ of the autochtonous Zator goose (Poland), and Scripnic and Modvala (2010) report the average egg mass of the Italian White goose of $160 \mathrm{~g}$.

Our study showed that the smallest loss of the egg mass by day 25 of incubation was in the egg group I $(10,98 \%)$, followed by the group II (11.38\%), and the largest was in the group III (11.71\%). Somewhat larger egg mass loss, but by day 26, was reported by Kucharska-Gaca et al. (2016b). By day 26 of incubation, the largest egg mass loss was reported by these authors to be in the group II (14.70\%), then in the group I $(14.57 \%)$, III $(14,36 \%)$, the smallest was that of the group IV (13.52\%), while the egg mass loss of all eggs, regardless of the weight group, was $14.52 \%$. The authors conclude that the heaviest eggs have the largest loss of humidity during the incubation period, and correspondingly, the lightest eggs have the smallest loss of humidity, which was also established by our research. Bobko and Svetlik (2002) reached a similar conclusion. Meir and $\operatorname{Ar}(1991 ; 2008)$ suggested that the loss of humidity in goose eggs during the incubation period depended on several factors (incubator type, thickness and penetrability of the shell), and that the loss of humidity between $10.5 \%$ and $13.0 \%$ was optimal for the normal embryo development. Rachwal (2008) established that egg weight affects embryo mortality, i.e. that lighter eggs have lower embryo mortality and vice versa.

In our study, the lightest eggs (egg weight group I) had the lowest relative gosling percentage in the egg mass
(65.24\%), followed by the medium weight eggs (group II) $66.61 \%$, the largest was in group III $(67.81 \%)$, and for all eggs (groups) the same was $66.51 \%$. The gosling mass ranged between $97.37 \mathrm{~g}$ (group I) and $129.06 \mathrm{~g}$ (group III), resulting in an average mass of $112.50 \mathrm{~g}$. Somewhat smaller average mass of the hatched goslings $(103.07 \mathrm{~g})$ was reported by Đermanovic et al. (2008), while Saatci et al. (2005) reported considerably lower one-day gosling mass in all strains of geese (the largest average gosling mass was that of the white feathered strain $-98.41 \mathrm{~g}$, and the smallest was the average gosling mass of the multicolored strain $-92.95 \mathrm{~g}$ ). The same authors further reported different values of the relative percentage of the gosling in the egg mass in various strains of the Turkish domestic goose, which ranged between $64.25 \%$ (black strain) and $65.39 \%$ (white strain), which was insignificantly lower than the same in our study. Although Kucharska-Gaca et al. (2016b) report larger average mass of all eggs (4 weight groups) of $179 \mathrm{~g}$, the average mass of the hatched goslings was considerably smaller (109 g), as well as the percentage of the gosling in the egg mass $(63.76 \%)$. However, the group I eggs (the lightest) had the least relative gosling percentage in the egg mass $(59.00 \%)$, while the eggs of the group IV had the largest $(65.60 \%)$. The relative gosling percentage according to the egg mass grew with the increase of the egg mass, which to a certain extent agreed with our findings, except that these authors reported a considerably lower gosling percentage.

Furthermore, Đermanovic et al. (2008) and Mitroviæ et al. (2017) have established positive correlation coefficients between the egg mass and the hatched offspring mass which showed medium, strong and very strong correlation between these traits.

Based on the studied effect of the egg mass on the incubation values and the gosling quality, it may be concluded 
that the eggs weighing over $200 \mathrm{~g}$ (group III) showed the poorest results, while the group II eggs (mass between 160 $\mathrm{g}$ and $180 \mathrm{~g}$ ) showed the best results, although the group I eggs (under $160 \mathrm{~g}$ ) demonstrated considerable incubation values.

\section{ACKNOWLEDGMENT}

The authors are grateful to the Ministry of Education, Science and Technological Development of the Republic of Serbia for sponsoring part of this study within project TR -31033 .

\section{REFERENCES}

Bednarczyk M., Rosiñski A. (1999): Comparison of egg hatchability and In Vitro Survival of goose embryos of various origins. Poultry Science, 78:579-585

Bobko M., Svetlik I.S. (2002): Weight losses of geese hatching eggs during incubation. Proc. of the International Scientific Conference Rearing of poultry and small livestock in the 3rd millennium, 17-18 September, Nitra, Slovakia, 115-119.

Đermanovic V., Anğelic-Buzadžic Gordana., Rajovic M., Puriæ V., Mitrovic S. (2008): The analysis of goose eggs incubation results of biracely half-breeds of geese. Proceedings of Research Papers, 14, (3-4): 135-142.

Kucharska-Gaca Joanna, Adamski M., Joanna KuŸniacka, Emilia Kowalska (2016a): Goose eggs hatching technique improvement with the use of pre-incubation. Acta. Sci. Pol. Zootechnica, 15 (2): 37-46.

Kucharska-Gaca Joanna, Adamski M., Joanna KuŸniacka, Emilia Kowalska (2016b): Influence of the weight of hatching eggs on the hatchability indices and on the body weight of geese in rearing and after fattening with oats. Acta. Sci. Pol. Zootechnica, 15(3): 67-82.

Mazanowski A., Adamski M. (2002): Evaluation of reproductive traits and egg quality in Astra $\mathrm{G}$ geese during the first reproductive period. Ann.Anim. Sci., 2 (2): 67-78.

Mazanowski A., Bernacki Z. (2006): Characteristics of reproductive traits and egg traits in Graylag goose (Anser anser L.) crossbreds. Arch. Geflügelk., 70 (2): 56-63.

Mazanowski A., Chelmonska B. (2000): The effects of reciprocal crossing of White Koluda and Greylag crossbred geese with Slovakian geese. Ann.Anim. Sci. - Rocz. Nauk. Zoot., 27 (4): 85-103.

Mitrovic S., Pandureviæ Tatjana., Milojevic Milena., Jokiæ Ž., Đermanovoic V., Mièic Svjetlana., Vlaèiæ Jelena. (2016): Effects of egg weight and shape index on incubation results of the White Italian Goose. VII Internationalni Scientific Agriculture Symposium, Agrosym 2016", 6-9 October 2016, Jahorina, Bosnia and Herzegovina.Proceedings, 2534-2540

Mitrovic S., Milojevic Milena; Đukic-Stojèic Mirjana (2017): Phenotype correlation of external and incubation traits of Italian white goose eggs and goslings after hatching. Indian J. Anim. Res. :52:497-501.

Meir M., Ar A. (1991): Compensation for seasonal changes in eggshell conductance and hatchability of goose eggs by dynamic control of egg water loss. Br. Poult. Sci., 32 (4): 723-732.

Meir M., Ar A. (2008): Changes in eggshell conductance, water loss and hatchability of layer hens with flock age and moulting. $B r$. Poult. Sci., 49 (6): 677-684.

Pakulska E., Badowski J., Bielinska H., Bednarczyk M. (2003): Wplyw wieku na cechy fizyczne jaj i wylêgowsc pisklat gêsi Bialych Koludzkich (Age effects of physical traits of eggs and hatchability of White Koluda goslings). Zesz. Nauk. Prz. Hod., 68(4): 71-77 (in Polish)

Rachwal A. (2008): Wplyw masy jaja na wylêgowosc, wielkosc pisklêcia, jego tempo wzrostu oraz wykorzystanie paszy (The influence of egg weight on hatchability, size of chick, its growth rate and utilization of pesture). Pol. Drob., 10: 13-16 (in Polish).

Rabsztyn A., Andres K., Dudek M. (2010): Variability, heritability and correlations of egg shape in the Zatorska goose. Journal of Central European Agriculture, 11(4): 433-436.

Razmaite V., ŠveistienP Ruta., Švirmickas G.J. (2014): Effect of laying stage on egg characteristics and yolk fatty acid profile from different-aged geese. Journal of Applied Animal Research, 42 (2): 127-132.

Rosiñski A. (2000): Analysis of direct and correlated effects of selection in two goose strains (in Polish). Rocz. AR Poznan, 309: 5-107.

Saatci M., Kirmizibayrak T., Aksoy A.R., Tilki M. (2005): Egg Weight, Shape Index and Hatching Weight and Interrelationships among These Traits in Native Turkish Geese with Different Coloured Feathers. Turk. J. Vet. Anim. Sci., 29: 353-357.

Scripnic Elena and Modvala Suzana (2010): Process of Increasing the Incubation Indices of Geese Eggs. Bulletin UASVM Animal Science and Biotechnologies, 67(1-2): 334-338. 